\title{
Cytological organization of the seminiferous epithelium in the Australian rodents Pseudomys australis and Notomys alexis
}

\author{
E. J. Peirce and W. G. Breed \\ Department of Anatomy and Histology, University of Adelaide, Adelaide, South Australia, 5001, \\ Australia
}

\begin{abstract}
Summary. Absolute and relative testis mass of two species of conilurine rodents, the plains rat (Pseudomys australis) and the hopping mouse (Notomys alexis), were markedly different. In plains rats the testis comprised $\sim 3 \%$ of body mass while in hopping mice they rarely accounted for more than $0.2 \%$. In both species, 8 cellular associations, or cycle stages, were recognized in the seminiferous epithelium. The relative freqencies, and hence durations, of Stages I to VIlI were $5 \cdot 1,7 \cdot 0,12 \cdot 5,10 \cdot 5,5 \cdot 4$, $25 \cdot 9,4 \cdot 4$ and $29 \cdot 0 \%$ of one cycle for plains rats $(\mathrm{N}=14)$, and $20 \cdot 4,10 \cdot 9,9 \cdot 6,8 \cdot 1,5 \cdot 1$, $20 \cdot 4,14 \cdot 7$ and $10 \cdot 8 \%$ for laboratory-bred hopping mice $(N=35)$. Generally, the relative durations of the cycle stages were very similar between plains rat individuals, but were variable between hopping mice. Also, organization of the seminiferous epithelium was less rigid in hopping mouse testes, and several anomalies were observed. These included: (1) the occurrence of $2-4$ cellular associations in about $20 \%$ (range $11 \cdot 3-33.9 \%$ ) of tubular cross-sections, (2) deviations in cellular composition in certain cycle stages from that usually observed, and (3) an increased incidence of degenerating cells, together with the presence of multinucleated 'giant' cells, within the seminiferous epithelium.
\end{abstract}

\section{Introduction}

In a previous comparative study of testis size and histology of some Australian conilurine rodents marked interspecific differences were found, with the smallest absolute and relative testis mass occurring in the hopping mouse, Notomys alexis, and the largest in the plains rat, Pseudomys australis (Breed, 1982a). In this previous investigation an assessment was made of the relative abundance of interstitial and tubular tissue, but the cytology of the seminiferous epithelium was not described.

In mammals two different methods have been used for categorizing stages of the cycle of the seminiferous epithelium (see Courot et al., 1970; Clermont, 1972; Berndtson, 1977). One, the 'tubular morphology' system (Berndtson, 1977), is based on changes in shape of spermatid nuclei, the maturation and meiotic stages of spermatocytes, and relative positions of germ cells, particularly spermatids, within the epithelium (Curtis, 1918; Roosen-Runge \& Giesel, 1950; Ortavant, 1959; Amann, 1962; Grocock \& Clarke, 1975). The second, the acrosomal system, is based on changes in shape of the acrosome and morphology of the maturing spermatids after staining with periodic acid-fuchsin sulphurous acid (PA-FSA) (Leblond \& Clermont, 1952). In the present study we have used the tubular morphology system to describe the cellular associations of the seminiferous epithelium in hopping mouse and plains rat testes. 


\section{Materials and Methods}

Animals. Plains rats and most of the hopping mice were obtained from colonies bred in the Medical School animal house, University of Adelaide. In addition, testes from 5 male hopping mice captured on Curtin Springs Station, N.T., in August 1984, and from several animals supplied by the Evolutionary Biology Unit, S.A. Museum, were also investigated.

Males of both species were maintained in groups of 4 or 5 in standard rat or mouse cages and were fed a diet of mouse cubes (Milling Industries, Mile End, S.A.) supplemented with mixed seed and fresh apple and carrot. Water was available at all times. The rooms in which the animals were housed had regulated temperature $\left(18-25^{\circ} \mathrm{C}\right)$ and lighting ( $12 \mathrm{~h}$ light: $12 \mathrm{~h}$ dark or $14 \mathrm{~h}$ light: $10 \mathrm{~h}$ dark) regimens. Plains rats and hopping mice both occur in the arid zone (Watts \& Aslin, 1981; Strahan, 1983), and so the regimens used fell within the ranges encountered by these species in the wild. Measurements of ambient and burrow temperatures taken at various times throughout the year (Lee et al., 1984) have indicated that hopping mice are subjected to a temperature range of $16-33^{\circ} \mathrm{C}$ while foraging or within their burrows. The daylength encountered by these animals in the wild varies and depends on the season and the animal's location within the species geographical range, but for Alice Springs $\left(23^{\circ} 56^{\prime} \mathrm{S}, 137^{\circ} 52^{\prime} \mathrm{E}\right.$, which is approximately mid-latitudinal range for this species of hopping mouse) maximum and minimum day lengths are $13 \mathrm{~h} 39 \mathrm{~min}$ light, $10 \mathrm{~h} 21 \mathrm{~min}$ dark, and $10 \mathrm{~h} 40 \mathrm{~min}$ light, $13 \mathrm{~h} 20 \mathrm{~min}$ dark respectively. Since reproductively active animals have been collected at all times of the year (Breed, 1982b), the effect of this variation in photoperiod and temperature on gonadal activity in the natural environment is probably negligible provided abundant food resources are available.

Tissue preparation. Sexually mature males of various ages, ranging from 2 months to 5 years, from both species were anaesthetized with pentobarbitone sodium (Nembutal: Abbott Ceva Chemicals, Hornsby, N.S.W.) at a dose rate of $6.0 \mathrm{mg} / 10 \mathrm{~g}$ body weight. The animals were then fixed by vascular perfusion through the left ventricle using the solutions and techniques of Forssman et al. (1977). The testes were removed, cut into slices using a sharp razor blade, and further fixed by immersion for $\mathrm{l}-2 \mathrm{~h}$ in the second perfusion fixative $(3 \%$ formaldehyde, $3 \%$ glutaraldehyde, $0.1 \%$ picric acid). The tissue was subsequently rinsed in $0.1 \mathrm{M}$-phosphate buffer, $\mathrm{pH} 7 \cdot 2$, post-fixed in $1 \%$ osmium tetroxide, dehydrated, and embedded in Spurr's resin. Plastic sections were cut at $0.5-1.0 \mu \mathrm{m}$ thickness on an ultramicrotome and stained with toluidine blue in borax before viewing under an Olympus BHT-2 or Vanox microscope.

In addition to the animals mentioned above, body and testicular weights were also obtained and analysed for most other plains rats and hopping mice killed during the past 3 years for other studies.

Determination of stages of the cycle of the seminiferous epithelium. The cycle of the seminiferous epithelium in plains rats and hopping mice was divided into 8 stages. The tubular morphology system was used in preference to the acrosomal system for several reasons. Firstly, the testicular tissue analysed was embedded in an epoxy resin (Spurr's) to minimize shrinkage artefacts and this medium, unlike paraffin wax, does not readily allow staining of the tissue with PA-FSA. Sections were therefore stained with toluidine blue in borax buffer, which does not distinguish Golgi derivatives from structures of other cellular origin. Secondly, the acrosome of the hopping mouse spermatid is small and consequently difficulty arises in distinguishing all steps of spermiogenesis at the light microscopical level with PA-FSA. The stages (which do not necessarily correspond to those used by previous investigators for other species) were defined as follows:

Stage $I$ began from the time of disappearance of spermatozoa from the tubule lumen and extended until the next generation of spermatid nuclei began to elongate.

Stage $I I$ was characterized by elongation of the spermatid nuclei but nuclear condensation had not yet begun.

Stage $I I I$ was the period of time during which elongated spermatid nuclei started to become more intensely stained with toluidine blue.

At the beginning of Stage $I V$, most of the spermatid nuclei had attained maximal staining intensity, but the more mature generation of primary spermatocytes had not yet undergone the maturation divisions.

During Stage $V$, either the older generation of primary spermatocytes was undergoing the meiotic divisions, or secondary spermatocytes were present.

Stage VI extended until the acrosomal granule became associated with the round spermatid nuclei. This coincided with the beginning of migration of the bundles of more mature elongated spermatids towards the tubule lumen.

Stage VII was characterized by the spreading of the acrosomal material over the anterior portion of the round spermatid nuclei and by further migration of the more mature spermatids towards the tubule lumen.

Stage VIII began from the time when mature spermatozoa lined the tubular lumen until their complete disappearance.

Two generations of primary spermatocytes and one generation of spermatids were present in Stages I-IV, whereas Stages VI-VIII had a single generation of spermatocytes and 2 spermatids.

Determination of the relative durations of the cycle stages. The relative durations of the various stages of the cycle of seminiferous epithelium were taken to correspond to the relative frequencies with which they appeared in crosssections of the seminiferous tubules. This is valid since, in randomly selected sections through seminiferous tubules, stages of long duration will appear more frequently, while those of shorter duration will appear less often, provided a large sample is taken (Clermont \& Trott, 1969).

For the plains rat, a minimum of 150 tubular cross-sections per animal, from at least 4 locations within the testis, were scored to determine cycle stage. Only cross-sections displaying a single cellular association were scored as only 4 cross-sections were found in the 14 animals examined in which more than one association was present. 
For hopping mice, a minimum of 100 tubular cross-sections from at least 3 different testicular sites were scored. All suitable cross-sectional profiles, including those in which more than one cellular association was present, were used in determining relative durations of the various stages. When more than one association was present in a cross-section, the area occupied by each was estimated and scored accordingly. This was possible since the boundaries between adjacent associations were generally well defined. The frequency with which tubular cross-sections displayed multiple cellular associations was also scored for each animal examined.

Any tubules that either appeared degenerate with respect to morphology of the seminiferous epithelium (these were rarely encountered) or were damaged during tissue preparation were not scored for either species.

\section{Results}

\section{Body and testicular mass of plains rats and hopping mice}

All males examined in this study had mature spermatozoa in their testes as well as in the excurrent ducts. Analysis of body, absolute and relative testis mass of animals killed during the past 3 years (see Table 1) showed that, in all adult male plains rats, the testes invariably weighed $1 \cdot 2-2 \cdot 5 \mathrm{~g}$ and comprised about $3 \%$ of body mass. By contrast, hopping mouse testes only weighed, on average, $30-60 \mathrm{mg}$, and seldom accounted for more than $0 \cdot 20 \%$ of body mass in all laboratory bred individuals regardless of their age or whether they had or had not recently mated with a female. The relative testicular mass of the wild caught hopping mice was even less due largely to the greater body mass of these individuals resulting from an abundance of subcutaneous body fat.

\section{Description of the cellular associations}

(a) Plains rat, Pseudomys australis (Figs 1-8).

Stage I. Type Al spermatogonia possessing pale ovoid nuclei with finely 'granular' chromatin were observed. Occasionally type B spermatogonia which had rounder nuclei and much more heterochromatin were also seen. However, in most sections the latter had divided to give rise to

Table 1. Body and testicular mass (mean \pm s.d.) of plains rats and hopping mice of various ages

\begin{tabular}{|c|c|c|c|c|c|}
\hline Species & $\begin{array}{c}\text { Age } \\
\text { (months) }\end{array}$ & $\begin{array}{l}\text { No. of } \\
\text { animals }\end{array}$ & $\begin{array}{c}\text { Body mass } \\
\text { (g) }\end{array}$ & $\begin{array}{l}\text { Testicular } \\
\text { mass* } \\
\text { (mg) }\end{array}$ & $\begin{array}{c}\text { Relative } \\
\text { testicular } \\
\text { mass } \\
(\%)\end{array}$ \\
\hline $\begin{array}{l}\text { Plains } \\
\text { rat }\end{array}$ & $\begin{array}{c}2-3 \\
4-6 \\
7-12 \\
13-24 \\
>24\end{array}$ & $\begin{array}{r}16 \\
20 \\
11 \\
12 \\
6\end{array}$ & $\begin{array}{l}43.4 \pm 6.4 \\
47.4 \pm 6.8 \\
54.8 \pm 9.3 \\
65.3 \pm 12.1 \\
60.4 \pm 8.0\end{array}$ & $\begin{array}{l}1370 \pm 210 \\
1470 \pm 360 \\
1610 \pm 280 \\
1830 \pm 440 \\
1720 \pm 420\end{array}$ & $\begin{array}{l}3.2 \pm 0.4 \\
3.1 \pm 0.7 \\
3.0 \pm 0.6 \\
2.9 \pm 0.8 \\
2.9 \pm 0.6\end{array}$ \\
\hline $\begin{array}{l}\text { Hopping } \\
\text { mouse }\end{array}$ & $\begin{array}{c}2-3 \\
4-6 \\
7-12 \\
13-24 \\
>24 \\
-+ \\
-+\end{array}$ & $\begin{array}{r}21 \\
43 \\
72 \\
5 \\
8 \\
5 \\
3\end{array}$ & $\begin{array}{l}29.8 \pm 3.8 \\
28.5 \pm 2.4 \\
30.3 \pm 3.4 \\
34.7 \pm 4.3 \\
34.0 \pm 5.8 \\
50.7 \pm 13.4 \\
32.5 \pm 2.1\end{array}$ & $\begin{array}{l}40.2 \pm 14.2 \\
45.8 \pm 13.7 \\
46.0 \pm 11.5 \\
47.5 \pm 5.5 \\
59.5 \pm 14.9 \\
40.4 \pm 2.1 \\
47.3 \pm 4.1\end{array}$ & $\begin{array}{l}0.14 \pm 0.05 \\
0.16 \pm 0.05 \\
0.15 \pm 0.04 \\
0.14 \pm 0.02 \\
0.18 \pm 0.06 \\
0.08 \pm 0.02 \\
0.15 \pm 0.02\end{array}$ \\
\hline
\end{tabular}

*Weight includes that for both testes in all cases.

†Wild caught animals, from Curtin Springs Station, N.T., captured in August 1984 and housed in the laboratory for 6-12 months before death.

$\ddagger$ Males had been used for breeding and had sired litters within the previous 2-month period. 

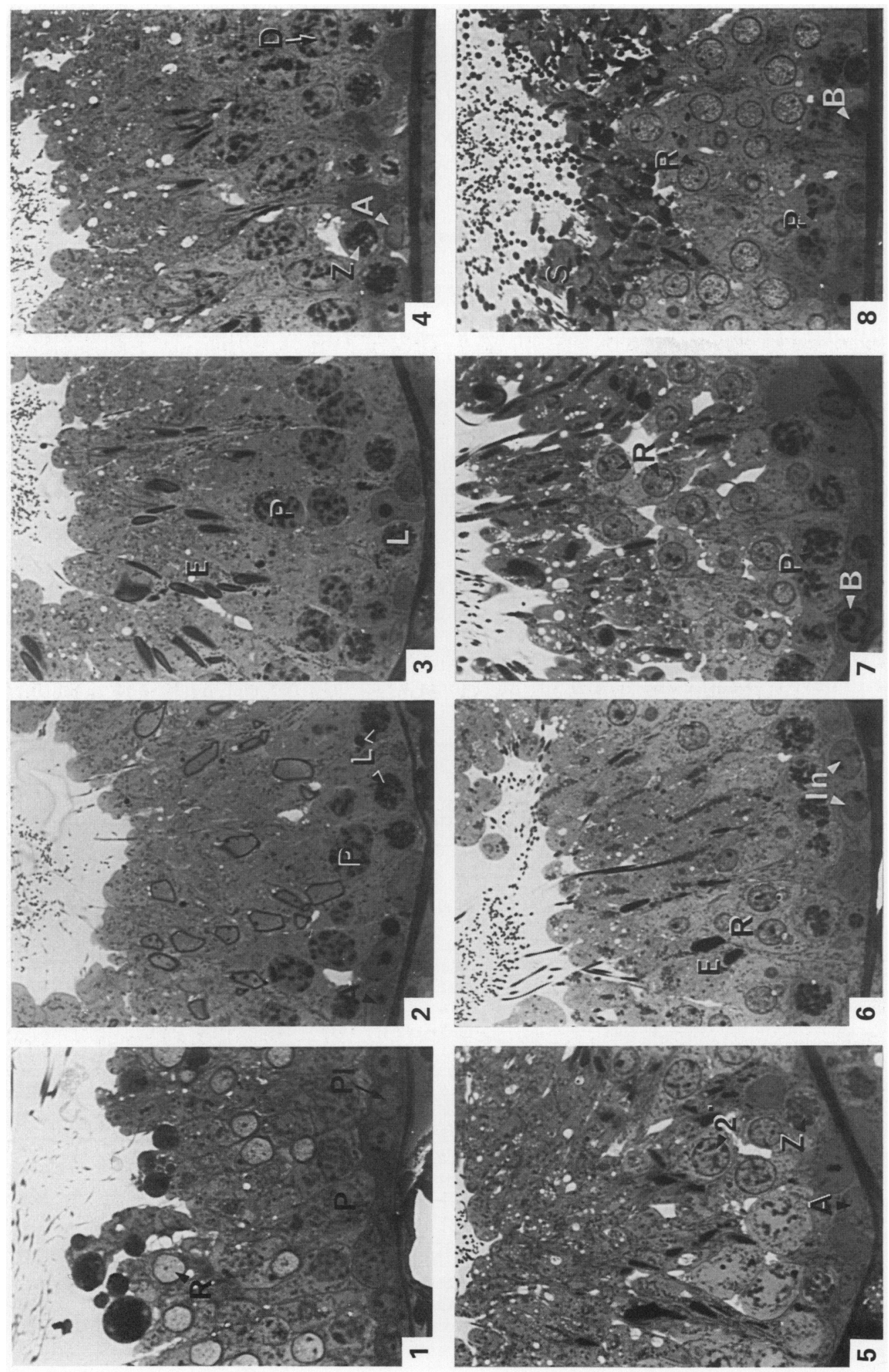

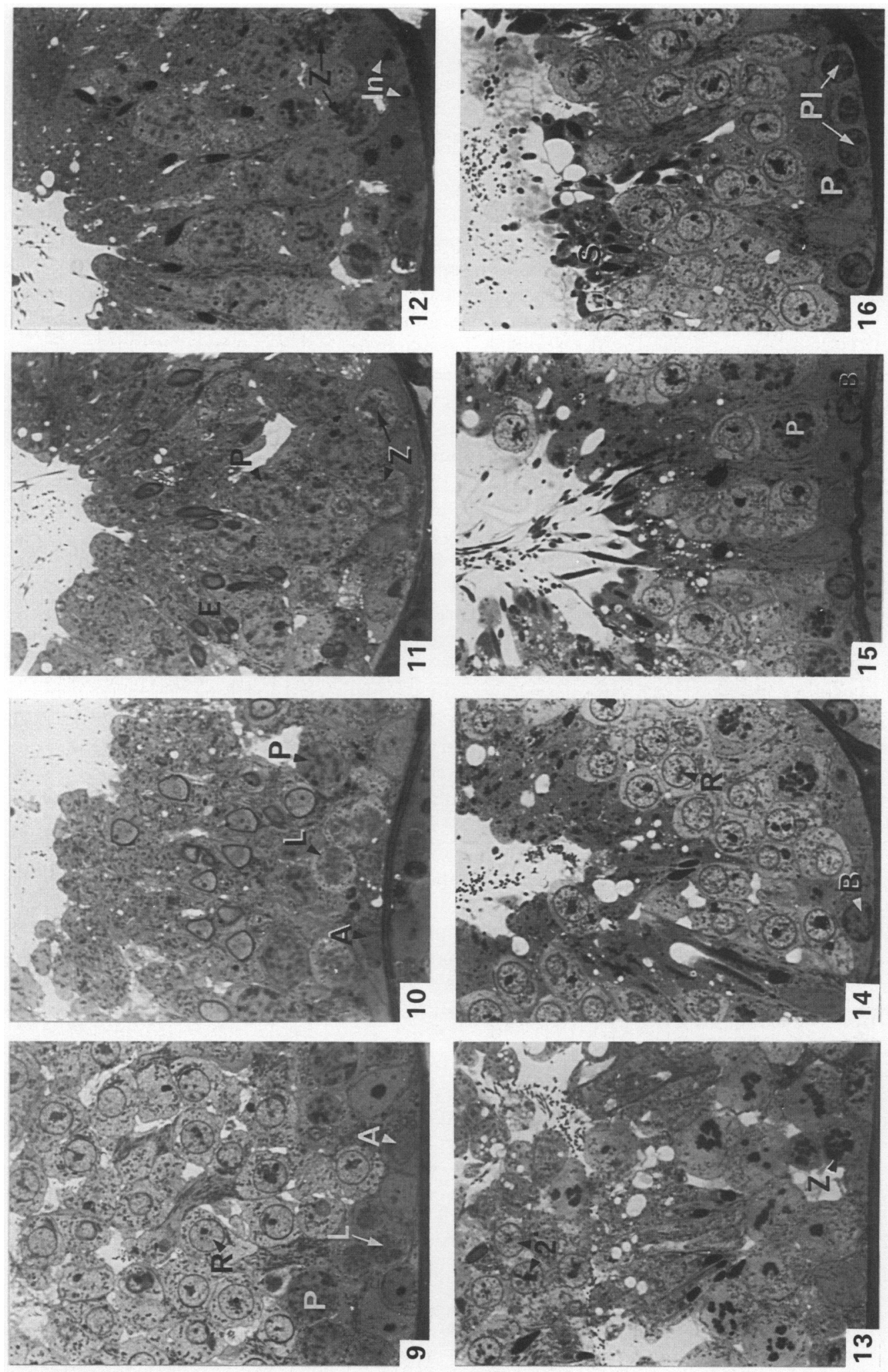
preleptotene primary spermatocytes which were similar in appearance to the B spermatogonia. One to two layers of primary spermatocytes with large nuclei containing thick chromosomes and a dense heterochromatic region overlaid the younger cell types and were considered to be at the pachytene stage. Round spermatids surrounded the tubular lumen and remnants of residual cytoplasm from the previously released spermatozoa were observed in the apical portions of Sertoli cells.

Stage II. Two types of spermatogonia were present, types Al and A2; the latter had a prominent darkly stained region of chromatin that was probably a nucleolus, and an indentation of the nuclear envelope was often seen. The early primary spermatocytes had proceeded to the leptotene stage as characterized by the filamentous appearance of their chromatin. The older primary spermatocyte population was still at pachytene and the spermatid nuclei had started to elongate.

Stage III. Spermatogonia appeared to be less abundant at this stage and were of types A1 and A2. The chromatin filaments of the leptotene spermatocytes tended to be thicker. A layer of pachytene spermatocytes were also present and the spermatid nuclei stained more intensely, and were considered to have begun condensation.

Stage $I V$. Types A1 and A2 spermatogonia were present; in a few cells, small clumps of heterochromatin appeared on the nuclear membrane. The chromatin of the younger primary spermatocyte population had thickened, giving the appearance of zygotene. The older spermatocytes were at pachytene or diplotene; their nuclei were large and tetrads were sometimes visible. The nuclei of the elongated spermatids were intensely stained.

Stage $V$. Spermatogonia and young primary spermatocytes had similar morphologies to those of the previous stage. Some of the older primary spermatocytes had undergone division and given rise to secondary spermatocytes with round nuclei in which there were several heterochromatic foci. Anaphase and metaphase configurations of dividing spermatocytes were also been. Bundles of elongated spermatids were embedded deep within invaginations of the Sertoli cells.

Stage VI. Types A1, A2 and intermediate (In) spermatogonia lined the basement membrane. The latter had nearly round nuclei containing a few heterochromatic regions close to the nuclear membrane. The chromatin threads in the primary spermatocyte nuclei were thicker and the cells were considered to be at the late zygotene to early pachytene stage. Up to 4 layers of round spermatids overlaid the spermatocytes and near the end of the stage the elongated spermatids were closer to the tubule lumen.

Stage VII. A greater number of spermatogonia occurred during this stage. Intermediate and B spermatogonia occupied most of the basal compartment and divisions were often seen. A single layer of pachytene spermatocytes and 3-4 layers of round spermatids were also present. Most of the elongated spermatids had moved towards the lumen.

Stage VIII. Type B spermatogonia were abundant and there were 1 or 2 layers of pachytene primary spermatocytes. Round spermatids were located closer to the lumen and the mature spermatozoa lined the lumen or had been released from the epithelium.

(b) Hopping mouse, Notomys alexis (Figs 9-16)

Stage I. Two types of A spermatogonia were present. The first, A1, had an ovoid nucleus with finely 'granular' chromatin; it was present in all the cellular associations. The second type, A2, was

Figs 1-16. Plastic, toluidine blue stained, sections of testis of the plains rat (Figs 1-8, Stages I-VIII respectively) and hopping mouse (Figs 9-16, Stages I-VIII respectively) illustrating the stages of the cycle of seminiferous epithelium. All sections are at the same magnification; $\times 780$. Abbreviations: $\mathrm{Se}=$ Sertoli cell nucleus; $\mathrm{A}, \mathrm{In}, \mathrm{B}=\mathrm{A}$, intermediate, \& B spermatogonia; $\mathrm{Pl}=$ preleptotene primary spermatocyte; $\mathrm{L}=$ leptotene primary spermatocyte; $\mathrm{Z}=$ zygotene primary spermatocyte; $\mathrm{P}=$ pachytene primary spermatocyte; $\mathrm{D}=$ diplotene primary spermatocyte; $2^{\circ}=$ secondary spermatocyte; $R=$ round spermatid; $E$ = elongated spermatid; $\mathrm{S}=$ mature spermatozoon. 
similar in appearance apart from a prominent nucleolus and several 'flakes' of chromatin adherent to the nuclear envelope. The younger generation of primary spermatocytes had nuclei with fine, thread-like, chromatin indicative of the leptotene stage, while the older generation possessed nuclei with thicker chromatin typical of pachytene. Generally, 3-4 layers of round spermatids surrounded the lumen.

Stage II. Type Al spermatogonia were observed as well as a morphologically different type of spermatogonium in which several distinct clumps of chromatin were apposed to the nuclear envelope and the nucleoplasm had a more granular appearance. These were designated type A3 spermatogonia. The two populations of primary spermatocytes were at leptotene and pachytene, and spermatids were elongating.

Stage III. Spermatogonia, that tended to be smaller than types A1 to A3, occupied the basal compartment. They possessed nearly round nuclei with moderately granular nucleoplasm and clumps of heterochromatin on the nuclear envelope and were designated intermediate (In) spermatogonia. During this stage, the chromatin filaments of the younger generation of primary spermatocytes had thickened, taking on the appearance of zygotene. Pachytene spermatocytes were also present and the spermatid nuclei were more intensely stained.

Stage $I V$. Intermediate spermatogonia were the predominant type, but pale type Al were also present. Zygotene spermatocytes were located above the spermatogonia and most of the older spermatocyte generation had entered the diplotene stage as characterized by the formation of tetrads. The nuclei of most of the elongated spermatids stained very intensely.

Stage $V$. During this stage, anaphase and metaphase configurations were common and, in a few sections, secondary spermatocytes with round nuclei containing a prominent heterochromatic region were also present. The young primary spermatocytes and spermatogonia appeared as in stage IV. Elongated spermatids occupied recesses between other cells of the epithelium.

Stage VI. The number of spermatogonia had increased by this stage. Intermediate spermatogonia had divided to give rise to B spermatogonia whose nuclei were more spherical and smaller in size. The nuclei were characterized by clumps of heterochromatin on the nuclear envelope and in the nucleoplasm. The spermatocytes were entering the pachytene stage, and newly formed round spermatids were located above them. Bundles of elongated spermatids were situated between the round spermatids.

Stage VII. Type B spermatogonia were abundant. Early pachytene spermatocytes, and 3-4 layers of round spermatids were positioned more adluminally. The elongated spermatids had moved towards the lumen and were located above the level of most of the round spermatids.

Stage VIII. Very few spermatogonia were present. The type B spermatogonia had divided to produce preleptotene primary spermatocytes in which the nuclear chromatin was more uniformly granular and less clumped than in B spermatogonia. By the end of the stage, many of the preleptotene spermatocytes had reached leptotene in which fine filaments rather than granules of chromatin were present in the nuclei. Pachytene primary spermatocytes and round spermatids occurred above the more immature germ cells. The spermatozoa lined the tubule lumen and some had been released from the epithelium.

\section{Deviations from the typical cellular associations}

A number of differences in the arrangement of the germ cells within the seminiferous epithelium were observed between the two species.

In the hopping mouse testis, minor variations in composition of the cellular associations from those described above were occasionally observed. In some cases, a particular generation of germ cells was seen at a slightly earlier or later stage of development than that present in a 'typical' association. For example, in Stage VIII of the cycle, type B spermatogonia were sometimes observed instead of the preleptotene primary spermatocytes which usually occurred within this stage (see Fig. 17). Likewise, the elongating spermatids of Stages III, IV and V occasionally had 

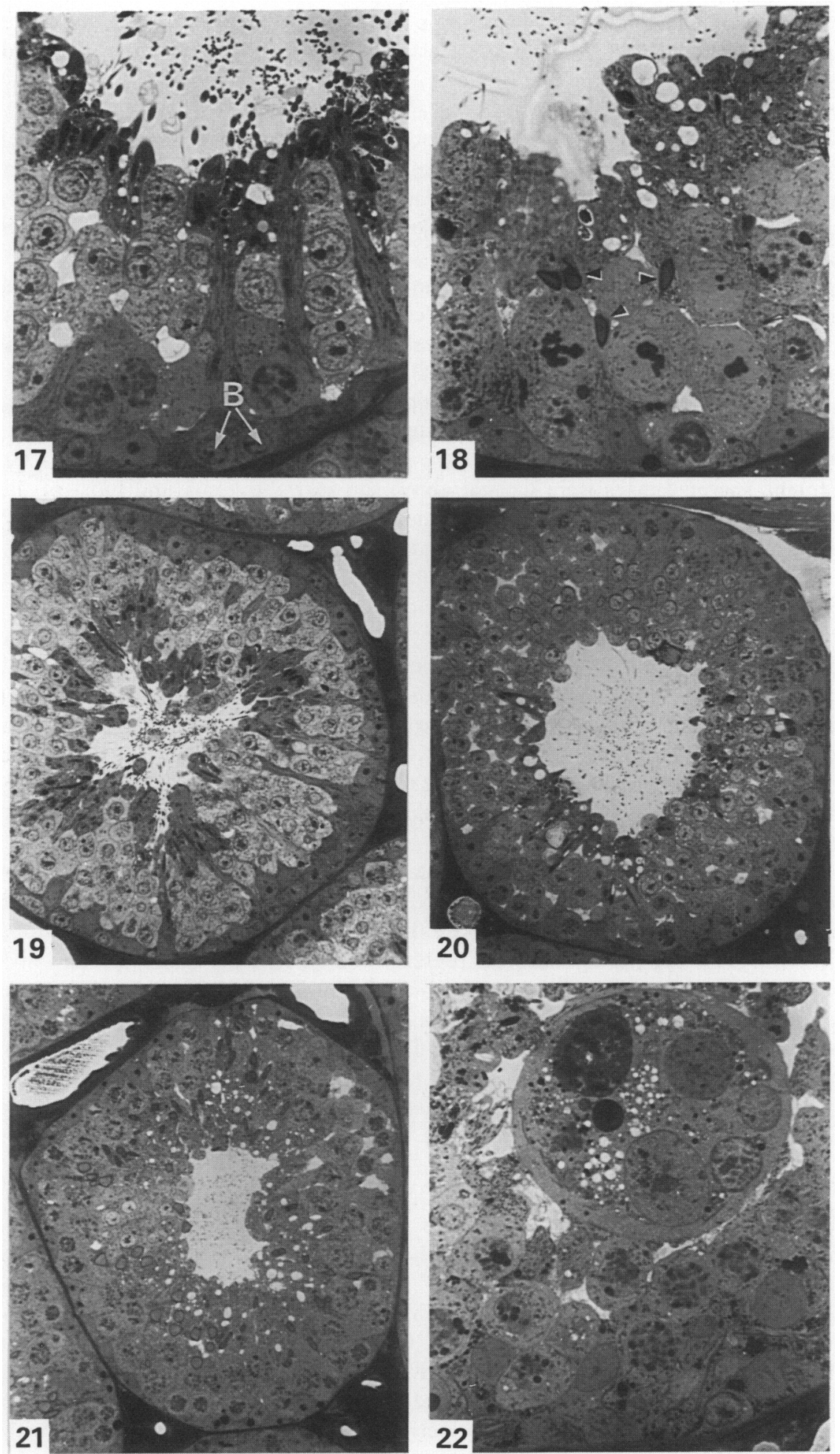
either more or less intensely stained nuclei than was usual for these stages (Fig. 18). On several occasions, associations were observed in which one generation of germ cells was completely absent from the epithelium (Fig. 19). Such deviations from the 'normal' were not seen in tubules of the plains rat testis.

For the testes of most rodents, including those of the laboratory rat and laboratory mouse, a particular cellular association occupies an extensive area of a seminiferous tubule (Curtis, 1918; Perey et al., 1961; Courot et al., 1970), and consequently, in cross-section, most tubules display a single cellular association. This was also the case in the plains rat testis. However, in the hopping mouse testis, an average of $19.9 \%$ (range $11 \cdot 3-33.9 \%$; 35 animals) of tubular cross-sections per animal displayed more than one cellular association, and as many as 4 associations in a single cross-section were observed (Figs 20 \& 21). This frequency of occurrence was similar regardless of the age of the animal.

Occasionally, multi-nucleated 'giant' cells were seen in tubules of the hopping mouse testis which were otherwise normal in appearance (Fig. 22). Although these cells were more common in testis sections from older animals, they were observed in the testes of a 3-month-old individual as well. Such cells were not seen in the plains rat testes.

No differences in testicular structure were observed between the laboratory bred hopping mice, regardless of whether they had or had not recently mated with a female, and those that had been caught in the wild. The irregularities in the arrangement and composition of the seminiferous epithelium were common to all groups of animals.

\section{Relative durations of stages of the cycle of the seminiferous epithelium}

The relative durations of stages of the cycle of the seminiferous epithelium were obtained by ascertaining the frequency with which they appeared in tubular cross-sections (see Table 2).

In plains rat testes, the most common associations were Stages VI and VIII, each comprising about $25 \%$ of all tubule cross-sections, whereas Stages I, V and VII were the least frequent each appearing in only $4-6 \%$ of cross-sections. In the testes of laboratory bred hopping mice, Stages 1 , VI and VII were the most frequent $(\sim 20 \%)$, while Stage V was the rarest.

The relative frequencies of the cellular associations of the wild caught hopping mice fell within the frequency ranges observed for the laboratory bred animals. Likewise, there was no difference in frequency of the associations between animals that had recently sired litters and those that had been housed in single sex groups (Table 2).

Figs 17-22. Anomalies present in hopping mouse seminiferous epithelium.

Fig. 17. Stage VIII tubule with B spermatogonia (B) and not preleptotene primary spermatocytes that are usually seen in this stage. $\times 790$.

Fig. 18. Stage V tubule. The elongated spermatid nuclei (arrowed) have not fully condensed; they correspond to Stage III spermatid nuclei. $\times 790$.

Fig. 19. Stage VII tubule demonstrating the absence of the pachytene primary spermatocyte cell generation normally present at this stage. $\times 315$.

Figs 20 \& 21. Tubular cross-sections with more than one cellular association present, Stages II, III \& IV (Fig. 21); Stages I, II \& III (Fig. 20). × 315 .

Fig. 22. Multinucleated 'giant' cell in the seminiferous epithelium. $\times 790$. 
Table 2. Relative frequencies (mean \pm s.d.) (indicative of relative durations) of stages of the cycle of the seminiferous epithelium in plains rats and in laboratory bred and wild caught hopping mice

\begin{tabular}{|c|c|c|c|c|}
\hline \multirow[b]{3}{*}{$\begin{array}{l}\text { Stage } \\
\text { of the } \\
\text { cycle }\end{array}$} & \multicolumn{4}{|c|}{ Relative frequency (\%) } \\
\hline & \multirow[b]{2}{*}{$\begin{array}{c}\text { Plains } \\
\text { rats } \\
(\mathrm{N}=14)\end{array}$} & \multicolumn{3}{|c|}{ Hopping mice } \\
\hline & & $\begin{array}{l}\text { Laboratory } \\
\text { bred stock } \\
(\mathrm{N}=35)\end{array}$ & $\begin{array}{l}\text { Recently } \\
\text { mated } \dagger \\
(\mathrm{N}=3)\end{array}$ & $\begin{array}{c}\text { Wild } \\
\text { caught* } \\
(\mathrm{N}=5)\end{array}$ \\
\hline I & $5 \cdot 1 \pm 1 \cdot 8$ & $20 \cdot 4 \pm 7 \cdot 7$ & $20 \cdot 1 \pm 5 \cdot 5$ & $21.9 \pm 4.0$ \\
\hline II & $7 \cdot 0 \pm 1 \cdot 2$ & $10 \cdot 9 \pm 4.0$ & $8.4 \pm 3.3$ & $8.3 \pm 1 \cdot 6$ \\
\hline III & $12 \cdot 5 \pm 2 \cdot 4$ & $9.6 \pm 3.7$ & $9.6 \pm 0.8$ & $7 \cdot 3 \pm 2 \cdot 7$ \\
\hline IV & $10.5 \pm 1.9$ & $8 \cdot 1 \pm 2 \cdot 6$ & $8.7 \pm 3.8$ & $10.2 \pm 2.7$ \\
\hline V & $5 \cdot 4 \pm 2 \cdot 0$ & $5 \cdot 1 \pm 2 \cdot 0$ & $8.6 \pm 0.9$ & $4.8 \pm 1.4$ \\
\hline VI & $25 \cdot 9 \pm 3 \cdot 2$ & $20 \cdot 4 \pm 8 \cdot 4$ & $17 \cdot 2 \pm 4 \cdot 2$ & $18.0 \pm 7.5$ \\
\hline VII & $4 \cdot 4 \pm 1 \cdot 3$ & $14.7 \pm 5.6$ & $17.5 \pm 4.5$ & $18.8 \pm 3.1$ \\
\hline VIII & $29 \cdot 0 \pm 3 \cdot 0$ & $10 \cdot 8 \pm 4 \cdot 2$ & $9 \cdot 8 \pm 1 \cdot 3$ & $10 \cdot 7 \pm 3 \cdot 6$ \\
\hline
\end{tabular}

*Animals from Curtin Springs Station, N.T., captured in August 1984, and housed in the laboratory for 6-12 months before death.

$\ddagger$ Males had been used for breeding and had sired litters within the previous 2-month period.

\section{Discussion}

The present study has confirmed the huge differences in absolute and relative testis mass of the two arid zone species of Australian conilurine rodents, the plains rat (Pseudomys australis), and the hopping mouse, (Notomys alexis). In plains rats, the testes were large (1.2-2.5 g), and comprised about $3 \%$ of body mass, whereas in hopping mice they were invariably very small $(30-60 \mathrm{mg})$, and rarely accounted for more than $0 \cdot 2 \%$ of body mass.

A study of the cycle of the seminiferous epithelium in males of these two species showed that it was basically similar to that documented for most other mammals with 8 cellular associations being recognizable in the testes of both species. Differences in tubular architecture were, however, evident between the 2 species and between the tubules of hopping mice and other rodents.

The same germ cell maturational stages did not always result in the corresponding cellular associations for the 2 species. For instance, in the plains rat testis, type B spermatogonia were present in Stages VII and VIII, preleptotene primary spermatocytes in Stage I, and leptotene primary spermatocytes in stage II. However, in the hopping mouse testis, type B spermatogonia were already present in Stage VI, preleptotene primary spermatocytes in Stage VIII, and leptotene primary spermatocytes in Stage I. Such differences in cellular composition of the stages between the species suggest small differences in timing of the divisions of the spermatogonia.

Organization of the seminiferous epithelium of plains rat tubules followed the pattern found in most species of rodents, including that of the laboratory rat (Roosen-Runge \& Giesel, 1950), laboratory mouse (Oakberg, 1956), golden hamster (Clermont, 1955), Chinese hamster (Oud \& de Rooij, 1977), and guinea-pig (Clermont, 1960), in which a single cellular association per tubular cross-section usually occurred. In the hopping mouse testis, however, approximately $20 \%$ of tubular cross-sections contained between 2 and 4 cellular associations. This was reminiscent of the situation in man (Clermont, 1963), and the baboon (Chowdhury \& Steinberger, 1976; Chowdhury \& Marshall, 1980), in which nearly all, and just under half of tubular cross-sections respectively, display more than one cellular association. In these species the occurrence of two or more cellular associations in the one tubular cross-section has been suggested as being in part related to the fact 
that individual cellular associations occupy smaller areas of the tubular epithelium (Heller \& Clermont, 1964; Chowdhury \& Marshall, 1980). The increased incidence of multiple cellular associations per tubular cross-section in the hopping mouse may be similarly related.

Another apparent difference of the seminiferous epithelium of the hopping mouse from that in other rodents so far studied (Leblond \& Clermont, 1952; Oakberg, 1956; Clermont, 1960) was a greater degree of variability in the cellular composition of the cycle stages. Cell types atypical to particular associations were sometimes evident in the hopping mouse testis, and occasionally an entire generation of germ cells was absent from an association. The former may indicate that the development of the various germ cell generations within an association is not as tightly integrated or synchronized as in most other species with a germ cell generation being at a slightly earlier or later stage of development than that considered 'typical' of the cellular association. It has been postulated that such shifts in the developmental timing of one generation of germ cells with respect to the others within an association of the human testis may be due to a 'looser control' (see Clermont, 1963) of spermatogenesis resulting in one population of cells beginning spermatogenesis a little earlier or later than would normally be expected. When a generation of germ cells is absent altogether, as has occasionally been found in the human testis, it may be due to lack of division of the spermatogonia in one particular cycle or subsequent death of a cell lineage.

In a few hopping mouse testes, multinucleated giant cells were seen in the seminiferous epithelium. The individuals in which these were found varied in age although there appeared to be an increased incidence in old animals. These cells have been observed in the human seminiferous epithelium in various circumstances (see Barham \& Berlin, 1974; Holstein \& Eckman, 1986), and their presence has been ascribed to degenerative processes within the testis sometimes arising from external noxes or pathogens resulting in defects of the intercellular bridges or the confluence of membranes between adjacent germ cells (see Holstein \& Eckman, 1986). The incidence of these, and other degenerative cells, in hopping mouse tubules of otherwise normal appearance was not related to testicular degeneration as all animals examined had viable sperm reserves present in the excurrent ducts. Their incidence appears, therefore, to reflect the normal attrition of germ cells associated with spermatogenesis in this species.

Species specific differences in the relative frequencies, and hence durations, of the stages of the cycle of the seminiferous epithelium, were observed between the plains rat and hopping mouse testes. The greatest differences were between Stages I and VIII. In the plains rat, Stage VIII was of relatively long duration, whilst Stage I was short. The opposite was the case in the hopping mouse testis. Such differences in the durations of these stages appear to be related to the timing of release of the mature spermatozoa from the epithelium and their disappearance from the tubule lumen. Likewise, the time required for the round spermatids to undergo the initial and cap phases of spermiogenesis, as indicated by differences in the relative durations of Stages VI and VII, appears to be species specific.

Relative durations of the cycle stages were more variable between individual male hopping mice than between plains rats. This may be for several reasons. Because multiple associations per tubular cross-section were common in the hopping mouse testis, a greater margin for error existed in defining the boundaries between them and determining the area occupied by each association. This could have contributed to the variability since relative durations were based on relative frequencies of occurrence. However, it is unlikely that this accounts for all the variation seen. Rather, in the light of the other anomalies observed in the hopping mouse testis, it is probable that the variability is associated with the seemingly looser overall control of the dynamics of germ cell production in these animals.

The only other species of rodent that we can find that has been described in the literature as having a testicular mass as small as that of the hopping mouse, apart from that of most other Notomys species (Breed, 1982a), is the mole vole (Ellobius lutescens) from Iran. In a study on this species, the testes were found to weigh only about $20 \mathrm{mg}$ for males of $60 \mathrm{~g}$ body weight (Stefan \& Steimer, 1978). However, despite this similarity in the occurrence of a very small testis, the structure 
of the seminiferous epithelium of mole voles and hopping mice was very different. The testes of mole voles rarely contained spermatids or spermatozoa, and spermatogenesis frequently ceased at the spermatocyte stage, suggesting a hypogonadic state (Stefan, 1967). In hopping mice, by contrast, all stages of spermatogenesis were clearly evident in all testes investigated, despite the variations in structure and organization of the seminiferous epithelium. Also, in hopping mice, the variability in the seminiferous epithelium was common to both the laboratory bred animals regardless of whether they had, or had not, recently sired young, and to wild caught individuals.

A number of other divergent features of the lower region of the male reproductive tract of the hopping mouse are also evident (Breed, 1986) and, when male hopping mice are dissected, testicular position varies from perianal to inguinal or even lower abdominal. In these animals an external scrotal swelling is often not evident, and the pampiniform plexus, unlike that of plains rats, is poorly developed and the testicular artery shows relatively little coiling. Nevertheless under laboratory conditions the breeding success of hopping mice is greater than that of plains rats, as indicated by both a higher number of litters born to the number of animals placed together in the breeding colony as pairs, and by the occurrence of a higher number of litters born per breeding pair (unpublished data). In the hopping mouse, therefore, the divergent anatomical features of the male reproductive tract, small testis size, variability in the structure of the seminiferous epithelium as well as in that of sperm morphology (see Breed \& Sarafis, 1983), do not appear to compromise fertility and appear to be the norm in this species of native Australian rodent.

We thank Mr Chris Leigh for technical assistance.

\section{References}

Amann, R.P. (1962) Reproductive capacity of dairy bulls. IV. Spermatogenesis and testicular germ cell degeneration. Am. J. Anat. 110,69-78.

Barham, S.S. \& Berlin, J.D. (1974) Fine structure and cytochemistry of testicular cells in men treated with testosterone propionate. Cell Tiss. Res. 148, 159-182.

Berndtson, W.E. (1977) Methods for quantifying mammalian spermatogenesis. A review. J. Anim. Sci. 44, 818-833.

Breed, W.G. (1982a) Morphological variation in the testes and accessory sex organs of Australian rodents in the genera Pseudomys and Notomys J. Reprod. Fert. 66, 607-613.

Breed, W.G. (1982b) Control of mammalian and avian reproduction in the Australian arid zone, with special reference to rodents. In Evolution of the Flora and Fauna of Arid Australia, pp. 185-190. Eds W. R. Barker \& P. J. M. Greenslade. Peacock Publications, Adelaide.

Breed, W.G. (1986) Comparative morphology and evolution of the male reproductive tract in the Australian hydromyine rodents (Muridae). J. Zool., Lond. 209, 607-629.

Breed, W.G. \& Sarafis, V. (1983) Variation in sperm head morphology in the Australian rodent Notomys alexis. Aust. J. Zool. 31, 313-316.

Chowdhury, A.K. \& Marshall, G. (1980) Irregular pattern of spermatogenesis in the baboon (Papio anubis) and its possible mechanism. In Testicular Development Structure and Function, pp. 129-137. Eds A. Steinberger \& E. Steinberger. Raven Press, New York.
Chowdhury, A.K. \& Steinberger, E. (1976) A study of germ cell morphology and duration of spermatogenic cycle in the baboon Papio anubis. Anat. Rec. 185, 155-169.

Clermont, Y. (1955) Cycle de l'epithelium seminal et mode de renouvellement des spermatogonies chez le hamster. Revue can. Biol. 3, 208-245.

Clermont, Y. (1960) Cycle of seminiferous epithelium of the guinea pig. A method for identification of the stages. Fert. Steril. 11, 563-573.

Clermont, Y. (1963) The cycle of seminiferous epithelium in man. Am. J. Anat. 112, 35 51 .

Clermont, Y. (1972) Kinetics of spermatogenesis in mammals: seminiferous epithelium cycle and spermatogonial renewal. Physiol. Rev. 52, 198-236.

Clermont, Y. \& Trott, M. (1969) Duration of the cycle of the seminiferous epithelium in the mouse and hamster determined by means of ${ }^{3} \mathrm{H}$-thymidine and autoradiography. Fert. Steril. 20, 805-817.

Courot, M., Hochereau-de-Reviers, M-T. \& Ortavant, R. (1970) Spermatogenesis. In The Testis, vol. 1, ch. 6, pp. 339-432. Eds A. D. Johnson, W. R. Gomes \& N. L. VanDemark. Academic Press, New York.

Curtis, G.M. (1918) The morphology of the mammalian seminiferous tubule. Am. J. Anat. 24, 339-394.

Forssman, W.G., Ito, S., Weihe, E., Aoki, A., Dym, M. \& Fawcett, D.W. (1977) An improved perfusion fixation method for the testis. Anat. Rec. 188, 307-314.

Grocock, C.A. \& Clarke, J.R. (1975) Spermatogenesis in mature and regressed testes of the vole (Microtus agretis) J. Reprod. Fert. 43, 461-470.

Heller, C.G. \& Clermont, Y. (1964) Kinetics of germinal 
epithelium in man. Recent Prog. Horm. Res. 20, 545-575.

Holstein, A.F. \& Eckmann, C. (1986) Multinucleated spermatocytes and spermatids in human seminiferous tubules. Andrologia 18, 5-16.

Leblond, C.P. \& Clermont, Y. (1952) Spermiogenesis of rat, mouse, hamster and guinea pig as revealed by the 'periodic acid-fuchsin sulfurous acid' technique. $\mathrm{Am}$. J. Anat. 90, 167-216.

Lee, A.K., Fleming, M.R. \& Happold, M. (1984) Microclimate, water economy and energetics of a desert rodent, Notomys alexis. In Arid Australia, pp. 315-326. Eds H. G. Cogger \& E. E. Cameron. Australian Museum, Sydney.

Oakberg, E.F. (1956) A description of spermatogenesis in the mouse and its use in analysis of the cycle of the seminiferous epithelium and germ cell renewal. Am.J. Anat. 99, 391-409.

Ortavant, R. (1959) Spermatogenesis and morphology of the spermatozoon. In Reproduction in Domestic Animals, vol. 2, ch. 1, pp. 1-50. Eds H. H. Cole \& P. T. Cupps. Academic Press, New York.
Oud, J.L. \& de Rooij, D.G. (1977) Spermatogenesis in the chinese hamster. Anat. Rec. 187, 113-124.

Perey, B., Clermont, Y. \& Leblond, C.P. (1961) The wave of the seminiferous epithelium in the rat. Am. J. Anat. 108, 47-77.

Roosen-Runge, E.C. \& Giesel, L.O. (1950) Quantitative studies on spermatogenesis in the albino rat. Am. $J$. Anat. 87, 1-30.

Stefan, Y. (1967) Morphologie et structure histologique du système génital mâle d'un rongeur d'Iran: Ellobius lutescens (Thomas). Archs Anat. Histol. Embryol. 50, 153-168.

Stefan, Y. \& Steimer, Th. (1978) The Leydig cell of a hypogonadic rodent (Ellobius lutescens, Th.): correlation between ultrastructure and biosynthetic activity. Biol. Reprod. 19,913-921.

Strahan, R. (1983) The Australian Museum Complete Book of Australian Mammals. Angus and Robertson, London.

Watts, C.H.S. \& Aslin, H.J. (1981) The Rodents of Australia. Angus and Robertson, London.

Received 25 July 1986 